\title{
Study on the Expression and Mechanism of Tumour- Derived IgG in Prostate Cancer
}

\author{
HONGMEI XIA [D
}

XIAOJIN LUO (1)

FENG ZHANG (D)

WEIHUA YIN (D)

*Author affiliations can be found in the back matter of this article

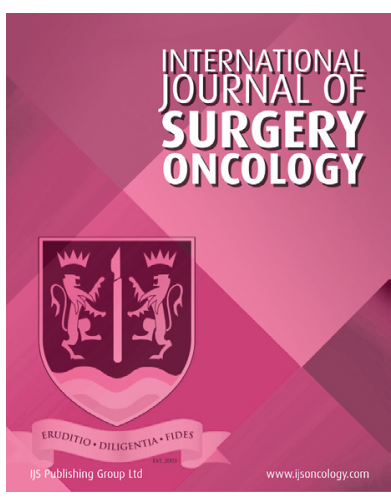

EXPERIMENTAL

RESEARCH

CORRESPONDING AUTHORS:

\section{Hongmei Xia}

Departments of Oncology, the People's Hospital of Yichun Affiliated to Clinical Medicine School of Yichun University in Jiangxi Province, Yichun, Jiangxi 336000, P.R. China xhm1976@126.com

\section{WeiHua Yin, MD\&PH.D}

Departments of Oncology, the People's Hospital of Yichun Affiliated to Clinical Medicine School of Yichun University in Jiangxi Province, Yichun, Jiangxi 336000, P.R. China; Key Laboratory for Research on Active Ingredients in Natural Medicine of Jiangxi Province, Yichun University, Yichun 336000, China

ywh1939@163.com of immunohistochemical pathological tissue sections collected from 50 patients with prostate cancer (PC) and 40 patients with prostatic hyperplasia from Yichun City People's Hospital between May 2010 and May 2014 was conducted. The experimental group had an average age of $70.8 \pm 2.7$ years (58 86 years old) and included 12 patients with low Ig expression and 38 with high Ig expression. The survival time of the former group was significantly longer than that of the latter group. In vitro, the expression of IgG protein and mRNA in PC3 cells was detected by Western blotting and RT-PCR. IgG expression was knocked down via small interfering RNA (siRNA), and the migration and invasion abilities of PC3 cells were assessed using a Transwell assay. Positive expression of tumour-derived IgG in prostate cancer can indicate poor prognosis of patients with prostate cancer, and high IgG expression promotes the invasion and metastasis of prostate cancer. Thus, IgG may become a therapeutic target in prostate cancer. 


\section{INTRODUCTION}

According to the classical immunological theory, immunoglobulins (Igs) are a unique product of B lymphocytes. Recent studies have shown that Igs (including IgM, IgG and IgA) can be expressed in many cells besides B cells, such as sperm cells, epithelial tissues and neuron cells [1-3]. However, high expression of IgG in epithelial-derived malignant tumour cells is positively correlated with the degree of tumour malignancy and promotes the proliferation of tumour cells, as indicated in solid tumours such as colon cancer, liver cancer and breast cancer [4-6]. Qiu et al. discovered the expression of IgG in breast cancer, colorectal cancer, liver cancer and other tissues and was the first to propose the new concept of "tumourderived Ig molecules" [7]. It is believed that the prominent feature of non-B Ig is its high expression in malignant transformed cells; in addition, its expression level is closely related to poor tumour differentiation and prognosis. Moreover, it promotes tumour invasion and metastasis [6-8]. There is few literature on immunoglobulin in prostate cancer, and the role of Ig in prostate cancer is relatively obscure. Beneduce et al. found that serum immunoglobulin (IgG, IgA or IgM) concentrations tended to be increased in patients with prostate cancer $[9,10]$. IgG expressed by prostate cancer cells is localized mainly in the cytoplasm, and its size is similar to that of IgG in normal cells [11-13]. Zheng et al.'s study showed that interfering with IgG expression in human procancer cells can inhibit tumour cell growth and accelerate apoptosis [14, 15]. However, the mechanism by which IgG from tumour tissue affects prostate cancer is unclear. In this study, IgG expression in prostate cancer and corresponding normal prostate tissues was assessed by immunohistochemistry (IHC), and its relationship with tumour proliferation and invasion was confirmed by in vitro experiments. Moreover, the influence of IgG on the progression of prostate cancer was discussed from an immunological perspective.

\section{MATERIALS AND METHODS CELL LINES AND REAGENTS}

The PC3 cell line was purchased from Guangzhou Leder Biotechnology Co. Ltd. A rabbit anti-human IgG antibody (primary antibody, concentration 7.5 $\mu \mathrm{g} / \mathrm{ml}$ ) was purchased from Abcam (ab109489). The secondary antibody system was a DAB kit purchased from Shanghai Genentech Co., Ltd. The sequences of the small interfering RNA (siRNA) plasmids were as follows: siRNA1: 5 '-ttugagcaagacaguuagg-3'; negative control (NC): 5 '-ucuuccgaacuggucaccu-3'. The siRNA sequences were designed and provided by Guangzhou Leder Biotechnology Co. Ltd.

\section{CELL TRANSFECTION}

siRNA plasmids were used in accordance with the plasmid transfection kit instructions. Each type of cell was divided into three groups: the experimental (siRNA1) group, the NC plasmid group, and the blank control (BC) group. Each group was seeded in 12 replicate wells, and the experiment was repeated 3 times.

\section{IGG EXPRESSION DETECTION}

Total RNA was extracted from cells according to the instructions for Trizol, and cDNA was synthesized by reverse transcription. Real-time RT-PCR was performed. Primers were provided by Guangzhou Leder Biotechnology Co. Ltd.:

\section{IgG- F: 5'- GCAGCCGGAGAACAACTACA-3',} IgG-R: 5'-TGGTTGTGCAGAGCCTCGAT-3'.

After cell lysis, centrifugation, electrophoresis, membrane transfer, rinsing, and sealing steps were performed, followed by a second rinsing step. The corresponding primary antibody was added, and the cells were incubated overnight at $4^{\circ} \mathrm{C}$. After washing, the cells were incubated with the secondary antibody (mouse/human ads-hrp) for $1 \mathrm{~h}$ for detection. IgG protein expression was detected by Western blotting.

\section{EVALUATION OF TUMOUR CELL PROLIFERATION VIA AN MTT ASSAY}

Three groups of prostate cancer cells were transfected in DMEM containing $10 \%$ foetal bovine serum. Cells were continuously cultured at $37^{\circ} \mathrm{C}$ in an atmosphere containing $5 \% \mathrm{CO}_{2}$. Cells at an appropriate confluence were harvested via $0.25 \%$ trypsin digestion and seeded in 96-well plates $\left(5 \times 10^{5}\right.$ cells in $200 \mu \mathrm{l} /$ well) in quintuplicate and were cultured for $48 \mathrm{~h}$. MTT reagent $(5 \mathrm{~g} / \mathrm{L}$ ) was added to each well $(150 \mu \mathrm{l} /$ well) and incubated for $4 \mathrm{~h}$. The supernatant was then discarded, and $100 \mu \mathrm{l}$ dimethyl sulfoxide was added with shaking for $15 \mathrm{~min}$. The optical density (OD) values at a wavelength of 492 $\mathrm{nm}$ were determined by a microplate assay, and the proliferation inhibition rate of PC3 cells was calculated: Cell proliferation inhibition rate $=(1-$ OD 492 in the experimental group/OD 492 in the BC group) $\times 100 \%$.

\section{TRANSWELL ASSAY}

The above transfected prostate cancer cell lines showed good cell growth, and $1 \times 10^{6}$ cells/L suspensions were prepared in serum-free medium. Then, $100 \mu \mathrm{l}$ was added to the upper chamber of the Transwell insert. The cell migration and invasion abilities were evaluated by a Transwell assay, which was repeated 3 times.

\section{IMMUNOHISTOCHEMICAL STAINING OF TISSUE SECTIONS}

Consent was obtained from the Yichun City People's Hospital ethics committee to discuss and collect surgical 
specimens from 50 surgical specimens from patients who underwent radical surgery for prostate cancer from the hospital's urological surgical department (between May 2010 and May 2014). The patients were 55 to 85 years old, with an average age of $70.8 \pm 2.7$ years. We selected prostate tissue samples from 40 patients with prostatic hyperplasia for comparison. These patients were 58 to 86 years old, with an average age of $70.5 \pm 3.1$ years. A test revealed no significant difference in age between the two groups. All patients were followed up regularly.

Immunohistochemical staining was performed via the $A B C$ method. Tissues were subjected to formalin fixation and paraffin embedding. Paraffin blocks were sectioned and subjected to dewaxing, processing for antigen repair, dropwise addition of $3 \%$ hydrogen peroxide at room temperature and incubation in a humidified chamber for $10 \mathrm{~min}$, and incubation with 3\% hydrogen peroxide to block peroxidase enzyme activity, and incubation for 30 min in $5 \%$ goat serum in a humidified chamber at room temperature. Then, the antibody (1:500) was added, with PBS instead of antibody solution as a negative control, and incubated at $4^{\circ} \mathrm{C}$ overnight. A fluorochromeconjugated secondary antibody was then added, and nuclei were counterstained. Slides were sealed with glycerol and imaged under a microscope.

All specimens were confirmed by two pathologists according to the most recent $\mathrm{WHO}$ pathological diagnostic criteria and were sent to Xiangya Hospital in Hunan for consultation in cases of uncertainty.

\section{STATISTICAL ANALYSIS}

The SPSS 13.0 statistical software package was used to perform statistical analysis, and measurement data are expressed as the means $\pm \mathrm{SD}$. Comparisons among groups were conducted with chi-square tests, t-tests and
ANOVA. Spearman rank correlation analysis was used to analyse correlations, and $\mathrm{P}<0.05$ was considered to indicate a statistically significant difference.

\section{RESULTS \\ EVALUATION OF IGG EXPRESSION \\ IN PROSTATE CANCER AND \\ PROSTATIC HYPERPLASIA USING AN IMMUNOHISTOCHEMICAL ASSAY}

The IgG detection rate in prostate hyperplasia tissues was $10 \%(4 / 40)$ by immunohistochemistry. However, in prostate cancer tissues, the expression rate of IgG was $96 \%$ (48/50), and IgG was localized mainly in the cytoplasm. In addition, cancer cells exhibited uneven staining. The difference between the two groups was statistically significant $(P<0.05)$ (see Figure 1 and Table 1 ).

\section{RELATIONSHIP BETWEEN IGG EXPRESSION IN PROSTATE CANCER TISSUES AND PATHOLOGICAL GRADE}

The expression of IgG increased as the Gleason score describing prostate cancer pathology increased. Spearman correlation analysis showed that IgG expression was significantly $(P<0.05)$ positively correlated with the Gleason score $(r=0.413, P<0.01)$, as shown in Table 2.

\begin{tabular}{llllll}
\hline GROUPS & CASES & IgG(+) & IgG(-) & $X^{2}$ & $P$ \\
\hline BPH & 40 & 4 & 36 & 67.372 & 0.000 \\
\hline CRPC & 50 & 48 & 2 & & \\
\hline
\end{tabular}

Table 1 Expression of IgG in prostatic hyperplasia and prostate cancer.

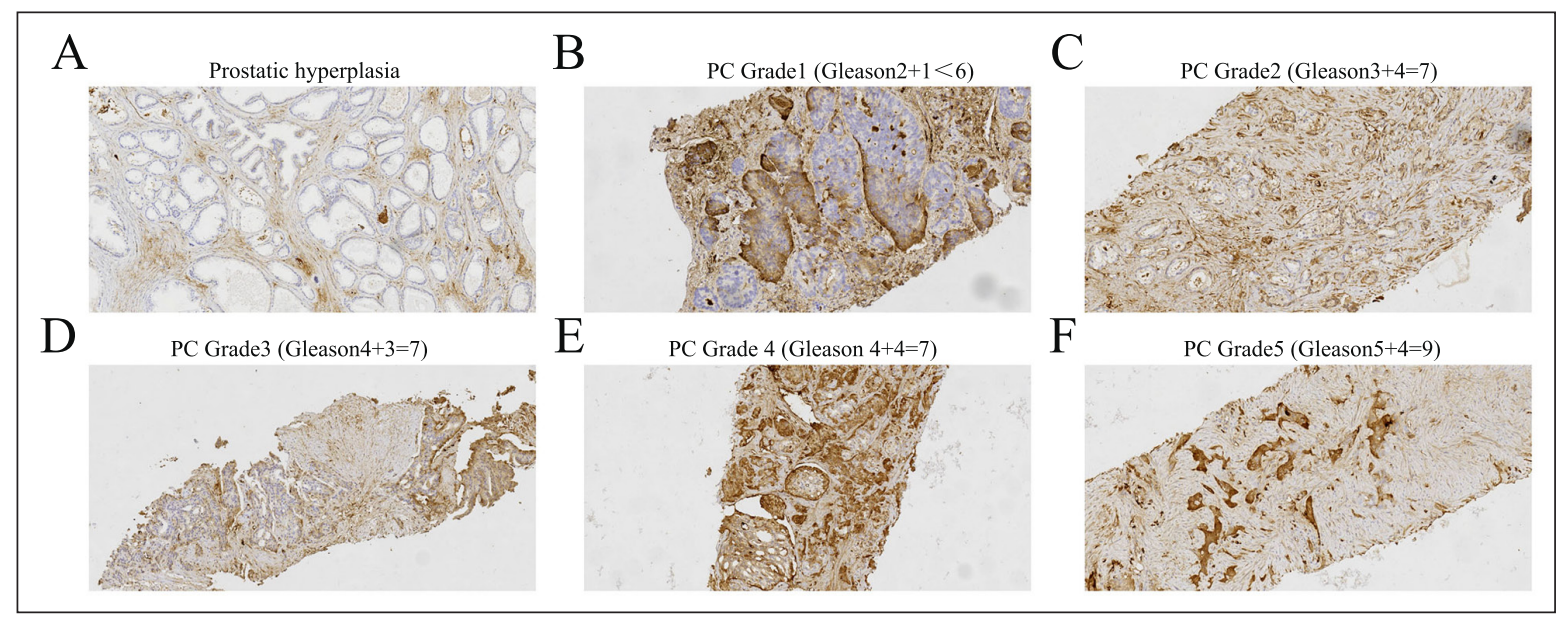

Figure 1 IgG expression in benign prostatic hyperplasia (BPH) and PC IgG was localized mainly in prostate cancer cells with heterogeneous staining, and the positive reactions were seen mainly in the cytoplasm (see figures 1. IgG expression in benign prostatic hyperplasia (BPH) (A) and CRPC (B, C, D, E, F) (×200)). The positive expression rate of IgG protein in prostate cancer tissue, which exhibited obvious positive staining, was $96 \%$ (48/45); however, the positive expression rate of IgG protein in BPH tissues was $10 \%(4 / 40)$. The difference between the two groups was statistically significant, as shown in table 1 (Expression of IgG in prostatic hyperplasia and prostate cancer). 


\section{SIRNA INHIBITED THE EXPRESSION OF IGG IN PC3 CELLS}

The IgG mRNA level in PC3 cells after RNA interference was measured by RT-PCR, as shown in Figure 1A. The relative expression level in the siRNA transfection group was significantly reduced $(0.12 \pm 0.03)$ compared with that in the NC group $(0.62 \pm 0.08)$ and the $B C$ group $(0.57 \pm 0.11)(P<0.01)$. The IgG protein level is shown in Figure $1 B$. No significant difference was found between the $B C$ group $(2.7 \pm 0.13)$ and the NC group (2.43 \pm 0.12$)(P>0.05)$, although the level "in the $\mathrm{BC}$ group was significantly higher than that in the siRNA transfection group $(1.42 \pm 0.11, \mathrm{P}<0.05)$. After transfection with siRNA, IgG expression in the BC group and the NC group did not change significantly, but IgG expression was inhibited in the siRNA interference group (see Figure 2).

\section{EVALUATION OF TUMOUR CELL PROLIFERATION ABILITY}

The above transfected PC-3 prostate cancer cell lines in each group were added to DMEM containing 10\% foetal bovine serum and seeded in 96-well plates $\left(5 \times 10^{5}\right.$ cells in $200 \mu \mathrm{l} /$ well). Five replicate wells were seeded, and $150 \mu \mathrm{l}$ of MTT reagent was added during the $72 \mathrm{~h}$ culture. The OD values at $492 \mathrm{~nm}$ (reference: $630 \mathrm{~nm}$ ) were measured via a microplate assay. siRNA significantly inhibited cell proliferation.

\section{MIGRATION AND INVASION OF PROSTATE CANCER CELLS}

To further verify the effect of tumour-derived IgG on the biological behaviour of prostate cancer cells, relevant siRNA was designed, and tumour-derived IgG was specifically knocked down to observe the changes in the biological behaviour of bladder cancer cells. After knockout of tumour-derived IgG, the migration and invasion abilities of bladder cancer cells in different fields were analysed. The numbers of migrated cells in the siNC, siRNA1 and siRNA2 groups of PC3 cells were 330.0 $\pm 16.7,20.0 \pm 12.2$ and $13.0 \pm 6.7$, respectively $(P<0.05)$. This finding suggests that high expression of IgG may enhance the migration and invasion abilities of bladder cancer cells and subsequently promote the development of bladder cancer (Figures 3 and 4).

\begin{tabular}{|c|c|c|c|c|c|c|}
\hline \multirow{3}{*}{$\begin{array}{l}\text { PATHOLOGICAL } \\
\text { GRADE }\end{array}$} & \multicolumn{4}{|c|}{ POSITIVE } & \multirow[t]{3}{*}{ R VALUE } & \multirow[t]{3}{*}{ P VALUE } \\
\hline & \multicolumn{4}{|c|}{ EXPRESSION OF IgG } & & \\
\hline & - & + & ++ & +++ & & \\
\hline Well differentiated & 1 & 7 & 6 & 4 & 0.413 & 0.003 \\
\hline $\begin{array}{l}\text { Moderately } \\
\text { differentiated }\end{array}$ & 1 & 2 & 5 & 9 & & \\
\hline Poorly differentiated & 0 & 1 & 4 & 10 & & \\
\hline
\end{tabular}

Table 2 Relationship between IgG expression and the pathological stage of prostate cancer.

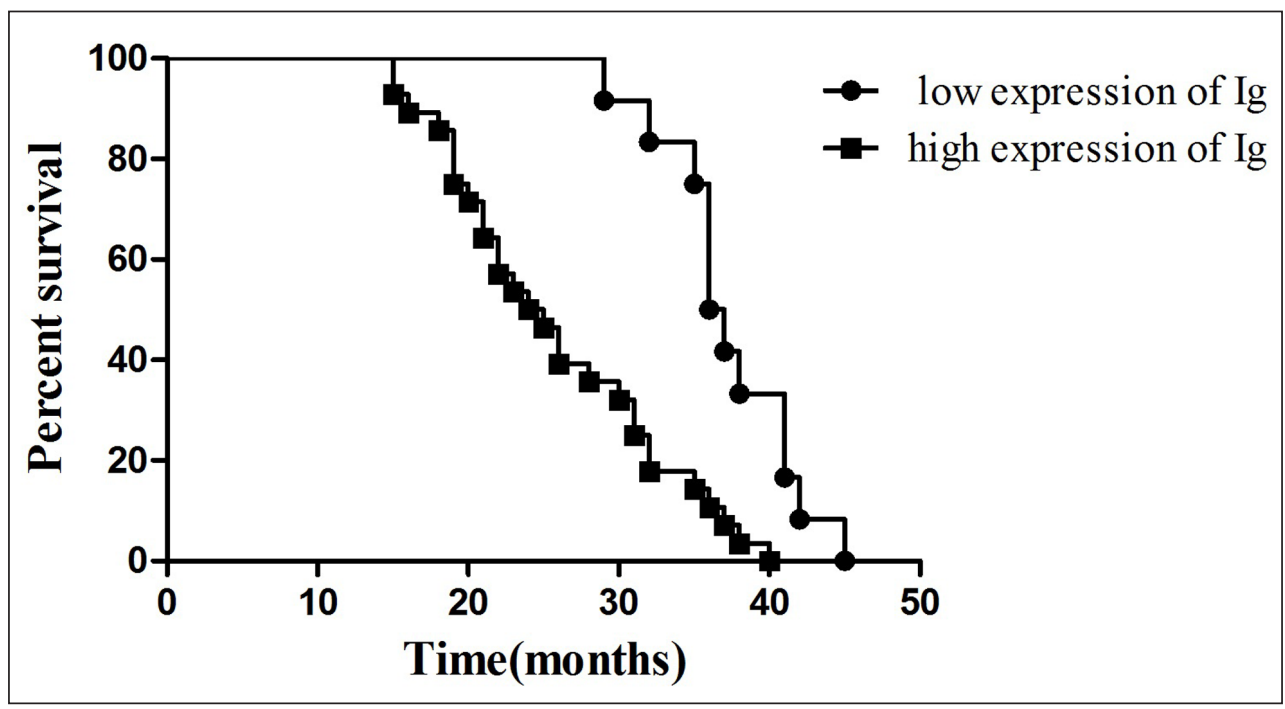

Figure 2 Relationship between IgG expression and survival time. The Gleason score in prostate cancer increases with increasing pathological abnormality, and the expression intensity of IgG was significantly increased. Spearman correlation analysis showed that the IgG expression intensity was significantly positively correlated with the Gleason score $(r=0.413, P<0.01)$. There were 12 patients with low expression $[\operatorname{Ig}(-)$ and $\operatorname{Ig}(+)]$ and 38 patients with high expression $[\operatorname{Ig}(++)$ and $\operatorname{Ig}(+++)]$. The survival period of prostate cancer patients in the low-expression group was $40.0 \pm 1.3$ months, significantly $(P<0.01)$ longer than that of patients in the highexpression group [(35.4 \pm 0.5$)$ months], as shown in table 2 and figure 2 . 


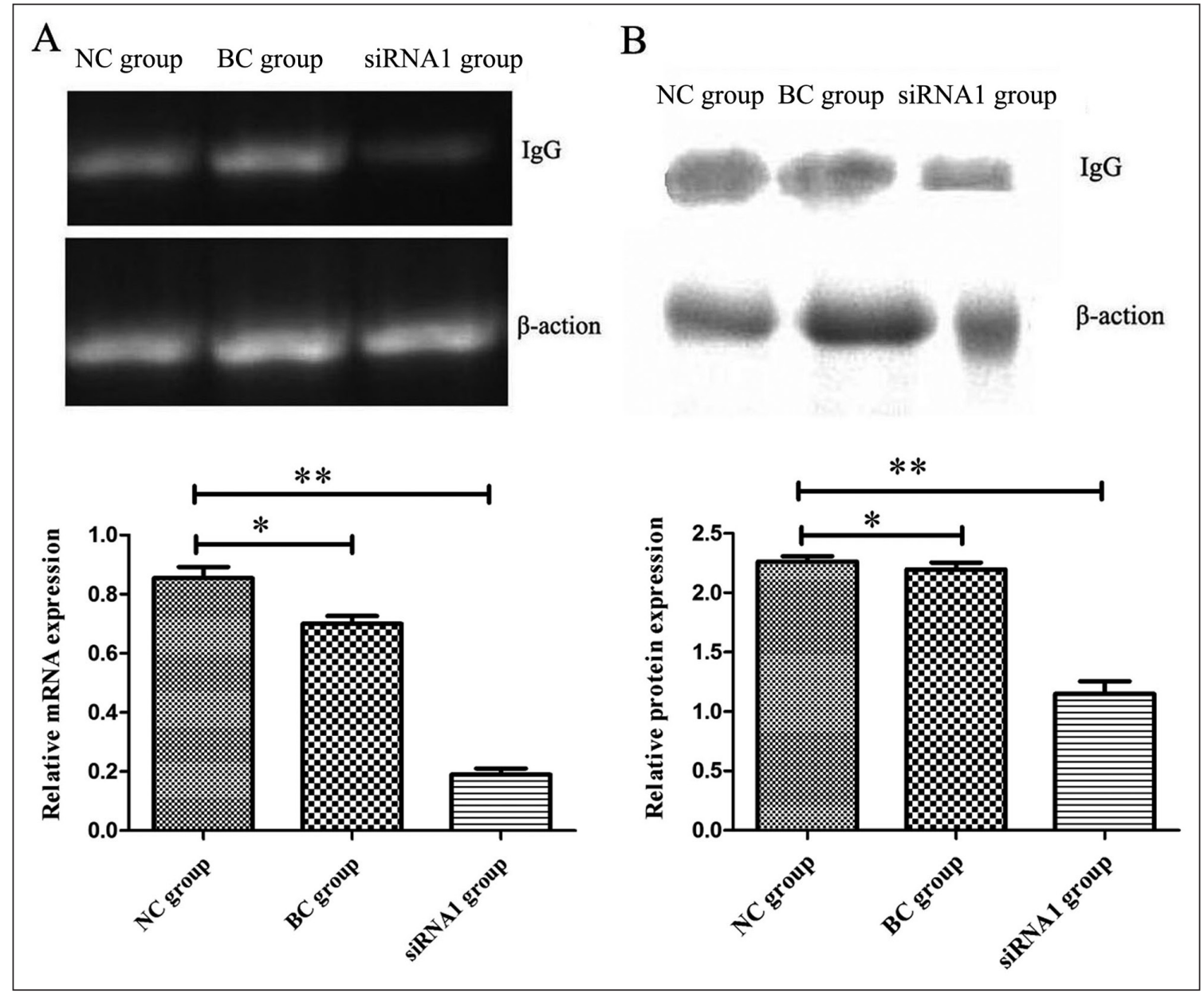

Figure 3 Expression of IgG. All cell lines were examined by RT-PCR and Western blotting, and the expression of IgG mRNA in the BC group and NC group was higher than that in the siRNA1 group. As shown, the relative protein expression levels were estimated by the grey scale (integrated optical density, IOD) values, and Ig protein expression was lower in the siRNA1 expression group than in the BC group and NC group. Ig protein expression did not differ significantly between the BC group and the NC group. The siRNA1 plasmid was successfully transfected into PC3 cells, and the transcription of the Ig protein was inhibited, as shown in figure 3.

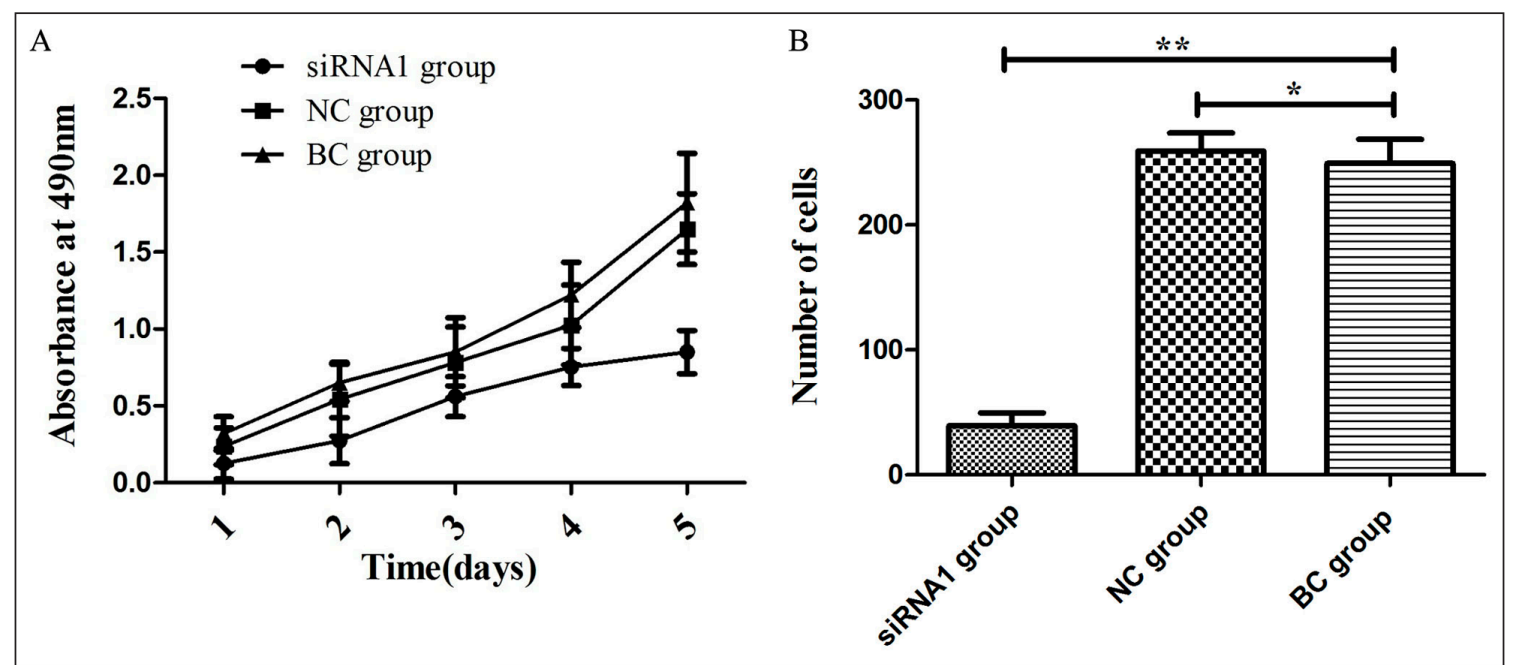

Figure 4 Proliferative and invasive abilities Cells from each group were collected at different time points and were magnified and counted after digestion. The cell concentration was adjusted to $1 \times 10^{5} \mathrm{cell} / \mathrm{s} / \mathrm{ml}$, and cells were inoculated in 96 -well plates, $(100 \mu \mathrm{l}$ per well). After adding $20 \mu \mathrm{l}$ of MTS solution to each well and incubating for $4 \mathrm{~h}$, the absorbance value of each well was measured at the wave length of $490 \mathrm{~nm}$ in a Multiskan MK3 enzyme labelling instrument to compare the proliferation activity in each group of cells. At the same time, $10^{5}$ cells were seeded in Transwell chambers, and $750 \mu \mathrm{l}$ of medium containing $10 \%$ foetal bovine serum was added to the lower chamber. The cells were incubated at $37^{\circ} \mathrm{C}$ in $5 \% \mathrm{CO}_{2}$ for 24 or $48 \mathrm{~h}$. Cells on the upper membrane surface were removed, and cells on the lower membrane surface were stained with $1 \%$ crystal violet and counted in 6 randomly selected fields. Proliferation and migration were enhanced in the BC group and NC group compared with the siRNA1 group. 


\section{DISCUSSION}

Prostate cancer is one of the most common malignancies of the urinary system in men and has the second-highest mortality rate in Western countries. In recent years, the incidence of prostate cancer in China has been increasing annually [16]. Castration-resistant prostate cancer (CRPC) develops within 18-24 months [17]. The lack of effective treatment for CRPC is the leading cause of death in prostate cancer patients. CRPC has been the focus of prostate cancer research. IgG is highly expressed in CRPC. Beneduce et al. indicated that serum IgG, IgA or IgM antibody concentrations were usually increased in prostate cancer (PC) patients $[18,19]$. Chen et al. showed that IgG expressed by PCa cells was the same size as that expressed in normal people and was co-localized in the cytoplasm and membrane but was mainly localized in the cytoplasm [20]. In this study, high expression of IgG in prostate cancer tissues was positively correlated with the pathological Gleason score and degree of malignancy of prostate cancer, and interfering with IgG expression inhibited cell growth and accelerated tumour cell apoptosis.

IgG is highly expressed in many solid tumours, such as colorectal cancer, breast cancer, and soft tissue sarcoma, and is derived from the Ig gene in malignant tumours, which can be transcribed and promotes the survival and proliferation of tumour cells [15, 20]. The literature reports that after blockade of IgG activity in the source tumour via RNA interference, the proliferation ability of tumour cells is significantly reduced and tumour cell apoptosis is accelerated [21-23]. Moreover, this interference with IgG activity can inhibit the growth of tumour cells, indicating that Ig produced by tumour cells can promote tumour cell proliferation [5, 14, 24]. Chen et al. found that the positive expression rate of Ig in soft tissue tumours was $97.4 \%$ and was positively correlated with the clinical stage [14]. The high expression of IgG in the tumours of patients in high-risk groups suggested that Ig could promote the proliferation and growth of tumour cells and could be used as a prognostic indicator for sarcomas $[25,26]$. This observation provides further confirmation that tumour-derived Ig exhibits biological activities very important for the growth of tumour cells. The expression of IgG in prostate cancer basically conforms to the expression patterns of IgG in the solid tumours mentioned above and is correlated with the malignancy degree of tumour tissues and interferes with the regulation of IgG-mediated tumour cell apoptosis. The results of this study showed that the expression of IgG in prostate cancer tissues is significantly higher than that in benign prostatic hyperplasia tissues. Additionally, we found a positive correlation between the tumour pathological grade and the IgG expression intensity ( $r=$ 0.413) - specifically, the higher the tumour malignancy degree, the higher was the IgG expression level. In contrast, the lower the malignancy degree, the lower was the expression of IgG. The differences were statistically significant ( $P=0.003$ ). We believe that IgG may act as a growth factor to promote tumour growth, but further studies are still needed to confirm this hypothesis. Some scholars found that the mechanism by which IgG promotes the growth of breast cancer cells involves the extracellular signal-regulated kinase 2 (ERK2) pathway [14]. In addition, in vitro experiments showed that after transfection of an FCGR1A siRNA interference plasmid into PC3 cells, the expression level of IgG mRNA was significantly reduced compared with that in the $\mathrm{BC}$ group and $N C$ group $(P<0.05)$. These results indicated that RNA interference was successful and inhibited the mRNA and protein expression of IgG. Ig of tumour cell origin was further confirmed to exhibit biological activity very important for the growth of tumour cells, but whether it affects the biological activity of prostate cancer remains to be further studied. Ig expression in tumour cells has certain significance in determining the differentiation degree and prognosis of prostate cancer and is expected to be an indicator and immune target for predicting the prognosis of prostate cancer. In the long term, IgG derived from prostate cancer tissue may reveal new mechanisms of the tumour cell microenvironment and growth. This study lays a foundation for further study of the effects of RNAi interference on the biological activity of prostate cancer and provides new ideas for gene therapy in prostate cancer, raising the question of whether Ig can be a new target gene in gene therapy for prostate cancer.

This study demonstrates that IgG is expressed in prostate cancer cells, a result that complements classical immunological theories. The expression of tumourderived IgG is positively correlated with the Gleason pathological score in prostate cancer, suggesting that the expression mechanism of tumour-derived IgG in prostate cancer should be further studied to further investigate the influence of the biological behaviour of prostate cancer cells and specific signalling pathways. Tumour-derived IgG will provide new molecular targets for the clinical treatment of prostate cancer.

\section{ABBREVIATIONS}

PC: Prostate cancer;

IgG: Immunoglobulin G; SiRNA: Small interfering RNA; CRPC: Castration-resistant prostate cancer; IHC: Immunohistochemistry

\section{ACKNOWLEDGEMENTS}

This work was supported by Natural Science Foundation of Jiangxi province (no. 20202BABL206079) and Project 
of Jiangxi Health and Health Commission (no.20161861). We would like to thank AJE for linguistic support.

\section{COMPETING INTERESTS}

The authors have no competing interests to declare.

\section{AUTHOR CONTRIBUTIONS}

WeiHua Yin conceived all ideal and designed part of the experiments. Fengzhang performed all parts of the experiments. Hongmei Xia and XiaoJin Luo designed part of the experiments. In addition, Hongmei Xia analysed all the data. Weihua Yin wrote the manuscript. All authors read and approved the final manuscript.

\section{AUTHOR AFFILIATIONS}

Hongmei Xia (iD) orcid.org/0000-0003-3487-987X Departments of Oncology, the People's Hospital of Yichun Affiliated to Clinical Medicine School of Yichun University in Jiangxi Province, Yichun, Jiangxi 336000, P.R. China

XiaoJin Luo (iD orcid.org/0000-0002-4007-5918 Departments of Oncology, the People's Hospital of Yichun Affiliated to Clinical Medicine School of Yichun University in Jiangxi Province, Yichun, Jiangxi 336000, P.R. China

Feng Zhang (D) orcid.org/0000-0003-4902-8955

Key Laboratory for Research on Active Ingredients in Natural Medicine of Jiangxi Province, Yichun University, Yichun 336000, China

Weihua Yin, MD\&PH.D (D) orcid.org/0000-0003-1358-604X Departments of Oncology, the People's Hospital of Yichun Affiliated to Clinical Medicine School of Yichun University in Jiangxi Province, Yichun, Jiangxi 336000, P.R. China; Key Laboratory for Research on Active Ingredients in Natural Medicine of Jiangxi Province, Yichun University, Yichun 336000, China

\section{REFERENCES}

1. Wei $\mathbf{Y}$, Lao XM, Xiao X, et al. Plasma Cell Polarization to the Immunoglobulin G Phenotype in Hepatocellular Carcinomas Involves Epigenetic Alterations and Promotes Hepatoma Progression in Mice. Gastroenterology. 2019; 156: 1890-1904.e1816. DOI: https://doi.org/10.1053/j. gastro.2019.01.250

2. Zhu X, Li C, Sun $\mathbf{X}$, et al. Immunoglobulin mRNA and protein expression in human oral epithelial tumor cells. Applied immunohistochemistry \& molecular morphology: AIMM. 2008; 16: 232-238. DOI: https://doi.org/10.1097/ PAI.0b013e31814c915a

3. Park DG, Woo BH, Lee BJ, et al. Porphyromonas gingivalisSerum Levels of Interleukin- 6 and Titers of Antibodies Against Could Be Potential Biomarkers for the Diagnosis of Oral Squamous Cell Carcinoma. International journal of molecular sciences. 2019; 20. DOI: https://doi. org/10.3390/ijms20112749

4. Wang L, Hoseini SS, Xu H, et al. Silencing Fc Domains in T cell-Engaging Bispecific Antibodies Improves T-cell Trafficking and Antitumor Potency. Cancer immunology research. 2019; 7: 2013-2024. DOI: https://doi. org/10.1158/2326-6066.CIR-19-0121

5. Wang Z, Geng Z, Shao W, et al. Cancer-derived sialylated IgG promotes tumor immune escape by binding to Siglecs on effector T cells. Cellular \& molecular immunology; 2019. DOI: https://doi.org/10.1038/s41423-019-0327-9

6. Geng Z ZH, Ye CX, Huang $\mathbf{Y}$, et al. Human colorectal cancer cells frequently express IgG and display unique Ig repertoire. World journal of gastrointestinal oncology. 2019; 11: 195-207. DOI: https://doi.org/10.4251/wjgo.v11.i3.195

7. Qiu X, Zhu X, Zhang L, et al. Human epithelial cancers secrete immunoglobulin g with unidentified specificity to promote growth and survival of tumor cells. Cancer research. 2003; 63: 6488-6495.

8. Shao W, Zhang $\mathbf{C}$, Liu $\mathbf{E}$, et al. Identification of Liver Epithelial Cell-derived Ig Expression in $\mu$ chain-deficient mice. Scientific reports. 2016; 6: 23669. DOI: https://doi. org/10.1038/srep23669

9. Beneduce L, Prayer-Galetti T, Giustinian AM, et al. Detection of prostate-specific antigen coupled to immunoglobulin $\mathrm{M}$ in prostate cancer patients. Cancer detection and prevention. 2007; 31: 402-407. DOI: https:// doi.org/10.1016/j.cdp.2007.10.005

10. Goufman IE, Yakovlev VN, Tikhonova NB, et al. Increased Blood Concentration of IgG Degradation Products in Prostate Cancer. Bulletin of experimental biology and medicine. 2019; 166: 651-655. DOI: https://doi. org/10.1007/s10517-019-04411-5

11. Cruz-Gallardo I, Martino L, Trotta R, et al. Resonance assignment of human LARP4A La module. Biomolecular NMR assignments. 2019; 13: 169-172. DOI: https://doi. org/10.1007/s12104-019-09871-4

12. Silva JAF, Biancardi MF, Stach-Machado DR, et al. The origin of prostate gland-secreted IgA and IgG. Scientific reports. 2017; 7: 16488. DOI: https://doi.org/10.1038/ s41598-017-16717-3

13. Lv WQ, Peng J, Wang HC, et al. Expression of cancer cellderived IgG and extra domain A-containing fibronectin in salivary adenoid cystic carcinoma. Archives of oral biology. 2017; 81: 15-20. DOI: https://doi.org/10.1016/j. archoralbio.2017.04.010

14. Chen Q, Wang J, Zhang Q, et al. Tumour cell-derived debris and IgG synergistically promote metastasis of pancreatic cancer by inducing inflammation via tumour-associated macrophages. British journal of cancer. 2019; 121: 786-795. DOI: https://doi.org/10.1038/s41416-019-0595-2

15. Xu Y, Chen B, Zheng S, et al. IgG silencing induces apoptosis and suppresses proliferation, migration and invasion in LNCaP prostate cancer cells. Cellular \& molecular biology letters. 2016; 21: 27. DOI: https://doi.org/10.1186/ s11658-016-0029-6 
16. Liu X, Yu C, Bi Y, et al. Trends and age-period-cohort effect on incidence and mortality of prostate cancer from 1990 to 2017 in China. Public health. 2019; 172: 70-80. DOI: https:// doi.org/10.1016/j.puhe.2019.04.016

17. Liu R, Zhou J, Xia S, et al. Androgen Deprivation Therapy and the Risk of Stroke in Patients with Prostate Cancer: An Updated Systematic Review and Meta-Analysis. Urologia internationalis. 2019; 1-8.

18. Yamamoto A, Kato M, Hattori K, et al. Propensity scorematched comparison of docetaxel and androgen receptor axis-targeted agents in patients with castration-resistant intraductal carcinoma of the prostate. BJU international; 2019. DOI: https://doi.org/10.1111/bju.14970

19. Terrisse S, Karamouza E, Parker CC, et al. Overall Survival in Men With Bone Metastases From CastrationResistant Prostate Cancer Treated With Bone-Targeting Radioisotopes: A Meta-analysis of Individual Patient Data From Randomized Clinical Trials. JAMA oncology; 2019. DOI: https://doi.org/10.1001/jamaoncol.2019.4097

20. Yu S, Li A, Liu Q, et al. Recent advances of bispecific antibodies in solid tumors. Journal of hematology \& oncology. 2017; 10: 155. DOI: https://doi.org/10.1186/ s13045-017-0522-z

21. Liu S, Huang Z, Zhang Q, et al. Profiling of isomer-specific IgG N-glycosylation in cohort of Chinese colorectal cancer patients. Biochimica et biophysica acta. General subjects.
2020; 1864: 129510. DOI: https://doi.org/10.1016/j.

bbagen.2019.129510

22. Jiang H, Kang B, Huang X, et al. Cancer IgG, a potential prognostic marker, promotes colorectal cancer progression. Chinese journal of cancer research = Chung-kuo yen cheng yen chiu. 2019; 31: 499-510. DOI: https://doi. org/10.21147/j.issn.1000-9604.2019.03.12

23. Gyurján I, Rosskopf S, Coronell JAL, et al. IgG based immunome analyses of breast cancer patients reveal underlying signaling pathways. Oncotarget. 2019; 10: 3491-3505. DOI: https://doi.org/10.18632/ oncotarget. 26834

24. Sustmann C, Dickopf S, Regula JT, et al. DuoMab: a novel CrossMab-based IgG-derived antibody format for enhanced antibody-dependent cell-mediated cytotoxicity. mAbs. 2019; 11: 1402-1414. DOI: https://doi.org/10.1080/194208 62.2019.1661736

25. Beneduce L, Castaldi F, Marino M, et al. Squamous cell carcinoma antigen-immunoglobulin $\mathrm{M}$ complexes as novel biomarkers for hepatocellular carcinoma. Cancer. 2005; 103: 2558-2565. DOI: https://doi.org/10.1002/cncr.21106

26. Langston ME, Bhalla A, Alderete JF, et al. Trichomonas vaginalis infection and prostate-specific antigen concentration: Insights into prostate involvement and prostate disease risk. The Prostate. 2019; 79: 1622-1628. DOI: https://doi.org/10.1002/pros.23886

TO CITE THIS ARTICLE:

Xia H, Luo X, Zhang F, Yin W. Study on the Expression and Mechanism of Tumour-Derived IgG in Prostate Cancer. International Journal of Surgery: Oncology. 2021; 6(1), 80-87. DOI: https://doi.org/10.29337/ijsonco.129

Submitted: 18 September 2021 Accepted: 09 October 2021 Published: 08 December 2021

COPYRIGHT:

(c) 2021 The Author(s). This is an open-access article distributed under the terms of the Creative Commons Attribution 4.0 International License (CC-BY 4.0), which permits unrestricted use, distribution, and reproduction in any medium, provided the original author and source are credited. See http://creativecommons.org/licenses/by/4.0/.

International Journal of Surgery: Oncology is a peer-reviewed open access journal published by IJS Publishing Group. 